Daphne J. Janssen

Luc J. Zimmermann

Paola Cogo

Aaron Hamvas

Kajsa Bohlin

Ingrid H. Luijendijk

Darcos Wattimena

Virgilio P. Carnielli

Dick Tibboel

\section{Decreased surfactant phosphatidylcholine synthesis in neonates with congenital diaphragmatic hernia during extracorporeal membrane oxygenation}

Received: 4 June 2008

Accepted: 10 June 2009

Published online: 7 July 2009

(C) The Author(s) 2009. This article is published with open access at Springerlink.com

\section{J. Janssen - I. H. Luijendijk · D. Tibboel ( ) \\ Department of Pediatrics and Pediatric Surgery, Intensive Care Erasmus MC-Sophia Children's Hospital, P.O. Box 2060, 3000 CB Rotterdam, The Netherlands e-mail: d.tibboel@erasmusmc.nl Tel.: +31-10-7036567}

D. J. Janssen

e-mail: d.janssen@erasmusmc.nl

\section{J. Zimmermann}

Division of Neonatology, University Hospital Maastricht, Maastricht, The Netherlands

P. Cogo

Department of Pediatrics,

University of Padova, Padua, Italy

\section{A. Hamvas · K. Bohlin}

Department of Pediatrics, Washington University/St. Louis Children's Hospital, St. Louis, USA

\section{K. Bohlin}

Division of Pediatrics, Karolinska University Hospital Huddinge and the Karolinska Institute, Stockholm, Sweden

\section{Wattimena}

Internal Medicine, Erasmus MC-Dijkzigt, Rotterdam, The Netherlands

\section{P. Carnielli}

Division of Neonatology, Children's Hospital Ancona, Ancona, Italy

Abstract Purpose: Congenital
diaphragmatic hernia (CDH) may
result in severe respiratory insuffi-
ciency with a high morbidity. The
role of a disturbed surfactant meta-
bolism in the pathogenesis of CDH is
unclear. We therefore studied endo-
genous surfactant metabolism in the
most severe CDH patients who
required extracorporeal membrane
oxygenation (ECMO).
Methods: Eleven neonates with
CDH who required ECMO and ten
ventilated neonates without signifi-
cant lung disease received a $24-\mathrm{h}$
infusion of the stable isotope [U- $\left.{ }^{13} \mathrm{C}\right]$
glucose. The ${ }^{13} \mathrm{C}-$ incorporation into
palmitic acid in surfactant phospha-
tidylcholine (PC) isolated from serial
tracheal aspirates was measured.

Mean PC concentration in epithelial lining fluid (ELF) was measured during the first 4 days of the study. Results: Fractional surfactant PC synthesis was decreased in $\mathrm{CDH}-$ ECMO patients compared to controls $(2.4 \pm 0.33$ vs. $8.0 \pm 2.4 \% /$ day, $p=0.04)$. The control group had a higher maximal enrichment $(0.18 \pm 0.03$ vs. $0.09 \pm 0.02 \mathrm{APE}$, $p=0.04)$ and reached this maximal enrichment earlier $(46.7 \pm 3.0$ vs. $69.4 \pm 6.6 \mathrm{~h}, p=0.004)$ compared to the CDH-ECMO group, which reflects higher and faster precursor incorporation in the control group. Surfactant PC concentration in ELF was similar in both groups.

Conclusion: These results show that $\mathrm{CDH}$ patients who require ECMO have a decreased surfactant PC synthesis, which may be part of the pathogenesis of severe pulmonary insufficiency and has a negative impact on weaning from ECMO.

Keywords Surfactant metabolism . Lung injury - Stable isotopes . Surfactant phosphatidylcholine . Congenital diaphragmatic hernia

\section{Introduction}

Congenital diaphragmatic hernia $(\mathrm{CDH})$ may result in severe neonatal pulmonary insufficiency due to lung hypoplasia, pulmonary hypertension and the sequelae of ventilatory support [1]. The mortality is variable depending on the case and center selection and the ability to use a variety of treatment modalities [2-4]. 
Several animal models, such as the surgically created $\mathrm{CDH}$ lamb model and the nitrofen-induced $\mathrm{CDH}$ rat model, suggest decreased surfactant parameters in lung tissue, but not on the individual cellular level [5-10]. In vitro studies in isolated type II cells of the $\mathrm{CDH}$ lamb model show decreased incorporation of precursor in surfactant phosphatidylcholine (PC), suggesting decreased surfactant synthesis $[8,9]$.

The scarce data in humans are more controversial. No difference in the amniotic lecithin/sphingomyelin ratio between $\mathrm{CDH}$ and control fetuses was found [11], but amniotic surfactant protein A (SP-A) was reported to be lower in $\mathrm{CDH}$ fetuses who died or required ECMO [12]. Autopsy studies in CDH infants showed decreased SP-A levels in the lungs [13, 14]. Recently, Boucherat et al. [15] concluded that no surfactant deficiency exists in lungs of fetuses with $\mathrm{CDH}$. Earlier, we showed that the concentration of surfactant PC in bronchoalveolar lavage from $\mathrm{CDH}$ patients was not different from control patients [16]. Within this context, Cogo et al. [17-19] studied surfactant metabolism with the use of stable isotopes in infants with $\mathrm{CDH}$ on mechanical ventilation, but not on ECMO, and compared them with ventilated control infants. In $\mathrm{CDH}$ infants without ECMO they found decreased amounts of PC and SP-A in the tracheal aspirates, a decreased surfactant disaturated PC (DSPC) pool size and a higher DSPC turnover rate, but no decreased synthesis of surfactant DSPC. In an earlier study, we did not find a change in surfactant PC pool size or in turnover rate in high-risk $\mathrm{CDH}$ patients who required ECMO when compared to infants with meconium aspiration on ECMO or to ventilated infants without ECMO [20].

Although different studies from the $\mathrm{CDH}$ study group did not reveal a benefit of routine use of exogenous surfactant, abnormalities in surfactant metabolism kinetics or secondary inactivation of surfactant due to the method of artificial ventilation cannot be excluded [21, 22]. We hypothesized that surfactant synthesis in $\mathrm{CDH}$ patients who require ECMO is decreased compared to control infants. Therefore, we studied the surfactant PC kinetics in vivo in $\mathrm{CDH}$ patients who required ECMO with the use of infused stable isotope tracers.

\section{Patients and methods}

\section{Patients}

The study was performed in the intensive care units of the Erasmus MC-Sophia in a 1.5-year period. We studied two groups of neonates (Table 1): neonates with left-sided $\mathrm{CDH}$ who required veno-arterial ECMO (CDH-ECMO) $(n=11)$ and a group of ventilated term neonates without
Table 1 Patient characteristics

\begin{tabular}{lll}
\hline & $\begin{array}{l}\text { CDH-ECMO } \\
n=11\end{array}$ & $\begin{array}{l}\text { Control } \\
n=10\end{array}$ \\
\hline Gestational age (week) & $38.2 \pm 0.8$ & $39.0 \pm 0.4$ \\
Birth weight (g) & $3,077 \pm 150$ & $3,189 \pm 237$ \\
Apgar at 5 min & $6.4 \pm 0.8$ & $7.0 \pm 1.5$ \\
Male/female & $7 / 4$ & $5 / 5$ \\
Pneumothorax $(n)^{\mathrm{a}}$ & 5 & 1 \\
Duration of ventilation (days) & $28.3 \pm 5.1$ & $25.6 \pm 9.9$ \\
Age at start study (h) & $42.9 \pm 4.5$ & $137.6 \pm 45.5^{\mathrm{b}}$ \\
Survivors $(n)$ & 5 & 8
\end{tabular}

${ }^{a}$ In all cases occurring before the start of ECMO, sometimes even directly after birth

b Significantly different $(p=0.03)$

significant lung disease (control) $(n=10)$. The diagnoses of the ten ventilated control patients were varied (gastroschisis, cerebral infarction, small to moderate omphalocele $(n=2)$, anal atresia, thymic cyst, spina bifida, pentalogy of Cantrell and hypoxic ischemic encephalopathy $(n=2)$ without primary pulmonary anomaly or signs of abnormal lung development at the time of the study. The study was approved by the local medical ethics committee, and all patients were studied after receiving written informed consent from the parents.

Our institution uses a standardized protocol for treatment of $\mathrm{CDH}$ patients, consisting of: planned vaginal delivery in prenatal diagnosed cases, immediate endotracheal intubation at birth, followed by high frequency oscillation (Sensormedics) as the primary ventilator mode. We used low settings: frequency $8-10 \mathrm{~Hz}$, MAP $12-14 \mathrm{mmHg}, \Delta P \quad 30-40 \mathrm{mmHg}$ and $\mathrm{FiO}_{2}$ to maintain preductal saturations $\geq 95 \%, P_{\mathrm{CO}_{2}}$ between 7.0 and $7.5 \mathrm{kPa}$, allowing permissive hypercapnia. Insertion of a double-lumen nasogastric tube with the application of continuous suctioning for decompression of the stomach, cardiac ultrasound to evaluate right-left shunting and structural defects, fluid restriction $(40-60 \mathrm{ml} / \mathrm{kg}$ body weight on day 1), no muscle paralysis, sedation with midazolam $[0.1 \mathrm{mg} /(\mathrm{kg} \mathrm{h})]$ and morphine $[5-15 \mathrm{mcg} /$ $(\mathrm{kg} \mathrm{h})$ ], and support of systemic blood pressure by dopamine and eventually norepinephrine [23].

The entry criteria for ECMO were: gestational age of $\geq 34$ weeks, birth weight of $\geq 2,000 \mathrm{~g}$, mechanical ventilation for $<7$ days, $\mathrm{AaDO}_{2}$ of $>600$ torr $(>80 \mathrm{kPa}$ ) for $8 \mathrm{~h}$ and $\mathrm{OI}>25$ for $4 \mathrm{~h}$. A minimal preductal $\mathrm{PaO}_{2}$ of $\geq 75$ torr $(\geq 10 \mathrm{kPa})$ was an additional entry criterion for $\mathrm{CDH}$ patients to at least ensure a reasonable chance of weaning from ECMO later. During ECMO, ventilator settings were routinely reduced to a peak inspiratory pressure of 9-12 $\mathrm{mmHg}\left(12-16 \mathrm{~cm} \mathrm{H}_{2} \mathrm{O}\right)$, positive endexpiratory pressure of $\sim 4 \mathrm{mmHg}\left(5-6 \mathrm{~cm} \mathrm{H}_{2} \mathrm{O}\right)$, respiratory rate of $10-15$ breaths/min, and $\mathrm{FiO}_{2}$ of $0.25-0.3$ using conventional ventilation (Babylog, Drager). 
Isotope infusion and sample collection

All included patients received a 24-h continuous intravenous infusion of $\left[\mathrm{U}_{-}{ }^{13} \mathrm{C}\right]$ glucose $[0.17 \mathrm{mg} /(\mathrm{kg} \mathrm{min})]$, Campro Scientific, Veenendaal, The Netherlands, and Cambridge Isotope Laboratories, Inc., Andover, MA). The start of the isotope infusion was defined as the start of the study $(t=0)$. Before and during the label infusion, $1 \mathrm{ml}$ of blood was drawn every $6 \mathrm{~h}$ for determination of ${ }^{13} \mathrm{C}$ enrichment of plasma glucose. Samples were collected in an EDTA tube, immediately placed on ice and centrifuged at $2,500 \mathrm{rpm}$ for $10 \mathrm{~min}$. The plasma was stored at $-70^{\circ} \mathrm{C}$ until it was analyzed. Tracheal aspirates were obtained every 4-6 h during the time the infant was intubated, with a maximum of 2 weeks. The tracheal suctioning was performed during routine patient care and did not deviate from the normal clinical care, which consisted of tracheal suctioning every nursing shift, or more frequently if it seemed clinically necessary. Tracheal aspirates were immediately placed at $-20^{\circ} \mathrm{C}$, until further processing.

\section{Analytical procedure}

The plasma and tracheal aspirates were processed as described before [19, 24]. Briefly, plasma was delipidated, and glucose was isolated and derivatized to an aldonitril pentacetate derivative [25]. Organic extraction was used to isolate surfactant lipids in the tracheal aspirates [26], and surfactant PC was recovered by thin layer chromatography [27]. Isotopic enrichments were measured by mass spectrometry, as described before [24]. The ${ }^{13} \mathrm{C}$-enrichments were expressed as atom percent excess (APE), which represents the increase in the percentage of ${ }^{13} \mathrm{C}$ atoms in total carbon dioxide from the combusted compounds above baseline enrichment (before infusion). Enrichments were corrected for the contribution of unlabeled carbon atoms added during derivatization.

Determination of composition and concentration

Fatty acid composition of surfactant PC and the amount of surfactant PC were determined by gas-chromatography (Hewlett-Packard, 5890 series II, Amstelveen, The Netherlands) [16]. The concentration of surfactant PC in the epithelial lining fluid (ELF) was calculated by correcting for dilution of the ELF during endotracheal suction: dilution factor $=[\mathrm{urea}]_{\text {serum }} /[\text { urea }]_{\text {supernatant }}[28]$.

\section{Calculations}

Calculations were performed as described before [24]. Time of first appearance $\left(T_{\text {app }}\right)$ is defined as the time delay between the start of the isotope infusion and the first appearance of the label in surfactant PC. Time of maximal enrichment $\left(T_{\max }\right)$ is the time where maximum enrichment is reached $\left(E_{\max }\right)$. Half-life of surfactant PC $\left(T_{1 / 2}\right)$ was calculated from the downslope of the enrichment versus time curve. Fractional synthesis time (FSR) of palmitic acid in surfactant $\mathrm{PC}$ represents the percentage of the total PC-palmitate pool synthesized de novo from plasma glucose per day.

\section{Data analyses}

Data are presented as mean \pm standard error of the mean (SEM). The non-parametric Mann-Whitney $U$ test was applied to compare groups. Spearman correlation was used to evaluate correlations between surfactant kinetic parameters, surfactant PC concentration and patient characteristics. Significance was accepted at a value of $p<0.05$ (two-sided).

\section{Results}

Seven CDH-ECMO patients were diagnosed prenatally and were born in our hospital; four were postnatal referrals. ECMO was started at $15.1 \pm 2.7 \mathrm{~h}$ after birth and had a duration of $226 \pm 34 \mathrm{~h}$. The time on ECMO before the start of the study was $27.8 \pm 4.2 \mathrm{~h}$. No baby received treatment with exogenous surfactant. All patients were successfully decannulated. The non-survivors in the CDH-ECMO group died at $28.2 \pm 5.5$ days of life because of therapy-resistant pulmonary hypertension. Unfortunately, lung body weight ratios are not available as no non-survivor autopsies were authorized. Two patients with hypoxic ischemic encephalopathy in the control group died because of severe cerebral damage on day 6, respectively, day 15 of life. Clinical characteristics are described in Table 1.

\section{Ventilatory parameters}

Nine $\mathrm{CDH}$ patients were ventilated with high frequency oscillation (HFO) before ECMO; two CDH patients were conventionally ventilated. Ventilation and oxygenation characteristics of the $\mathrm{CDH}$ patients before the start of ECMO were as follows: mean airway pressure (MAP) was $13.5 \pm 1.4 \mathrm{mmHg}\left(18.3 \pm 1.9 \mathrm{~cm} \mathrm{H}_{2} \mathrm{O}\right)$, oxygenation index $\left[\mathrm{OI}=\left(\mathrm{MAP} \times \mathrm{FiO}_{2}\right) / \mathrm{PaO}_{2} \mathrm{I}\right]$ was $40.6 \pm 8.1$, and the alveolar-arterial oxygen gradient $\left(\mathrm{AaDO}_{2}=\mathrm{PaO}_{2}\right.$ $\left.\left[\left(713 \times \mathrm{FiO}_{2}\right)-\left(\mathrm{PaCO}_{2} / 0.8\right)\right]\right)$ was $593.0 \pm 10.2$ torr $(79 \mathrm{kPa})$. The ten control patients were conventionally ventilated for $26 \pm 10$ days following surgery or because of apneic attacks. These patients had mild ventilatory settings: $\mathrm{FiO}_{2}: 0.26 \pm 0.03$, MAP: $5.9 \pm 0.6 \mathrm{mmHg}$ 
Table 2 Surfactant kinetic parameters

\begin{tabular}{lccl}
\hline & CDH-ECMO $n=11$ & Control $n=10$ & $p$ Value \\
\hline FSR (\%/day) & $2.4 \pm 0.3$ & $8.0 \pm 2.4$ & 0.04 \\
$T_{\text {app }}$ (h) & $18.0 \pm 2.6$ & $11.7 \pm 1.1$ & 0.11 \\
$T_{\max }$ (h) & $69.8 \pm 6.6$ & $46.7 \pm 3.0$ & 0.004 \\
$E_{\max }$ (APE) & $0.09 \pm 0.02$ & $0.18 \pm 0.03$ & 0.04 \\
Half life (h) & $69.0 \pm 10.3$ & $63.4 \pm 10.7$ & 0.79 \\
$E_{\text {gluc }}$ (APE) & $2.0 \pm 0.1$ & $2.2 \pm 0.3$ & 0.75 \\
PC (mg/ml ELF) & $6.6 \pm 1.9$ & $12.8 \pm 2.6$ & 0.78 \\
\hline
\end{tabular}

Phosphatidylcholine (PC) concentration in epithelial lining fluid (ELF) during the first 4 days of the study. Data are expressed as mean \pm standard error of mean (SEM)

FSR Fractional surfactant synthesis, $T_{a p p}$ time of first appearance of the label, $T_{\max }$ time of maximal enrichment, $E_{\max }$ maximal enrichment expressed as atom percent excess (APE), $E_{\text {gluc }}$ mean enrichment of plasma glucose in steady state

The non-parametric Mann-Whitney $U$ test was applied to compare groups

$\left(8.0 \pm 0.8 \mathrm{~cm} \mathrm{H}_{2} \mathrm{O}\right)$, ventilatory rate: $31 \pm 4 / \mathrm{min}$, positive inspiratory pressure (PIP): $\quad 14.1 \pm 1.3 \mathrm{mmHg}$ $\left(19.2 \pm 1.8 \mathrm{~cm} \mathrm{H}_{2} \mathrm{O}\right)$ and positive end-expiratory pressure (PEEP): $3.2 \pm 0.1 \mathrm{mmHg}\left(4.4 \pm 0.2 \mathrm{~cm} \mathrm{H}_{2} \mathrm{O}\right)$.

\section{Surfactant kinetic parameters (Table 2)}

The ${ }^{13} \mathrm{C}$-enrichment of plasma glucose was in steady state $\left(E_{\text {gluc }}\right)$ in all infants between $t=6$ and $24 \mathrm{~h}$, and was similar in both groups (Table 2). Despite a larger blood volume in ECMO patients due to the extracorporeal circuit, this was expected as the plateau ${ }^{13} \mathrm{C}$ enrichment of glucose during a continuous infusion is determined by the rate of appearance of glucose in the plasma and not by the volume of distribution. Figure 1 shows the ${ }^{13} \mathrm{C}$-glucose incorporation of surfactant PC palmitate in sequential tracheal aspirates in the $\mathrm{CDH}$ ECMO patients and control patients. The incorporation of ${ }^{13} \mathrm{C}$ from the precursor glucose into surfactant PC palmitate started somewhat later $\left(T_{\mathrm{app}}\right)$ in the $\mathrm{CDH}-$ ECMO patients, but the difference with controls was not significant. The CDH-ECMO group had a significantly lower maximal enrichment $\left(E_{\max }\right)$, which also was reached later $\left(T_{\max }\right)$ compared to the control group. These indices reflect reduced precursor incorporation into surfactant $\mathrm{PC}$ in the CDH-ECMO group (Table 2). FSR was more than three times lower in CDH-ECMO patients than in control patients, but the half-life of label disappearance from surfactant PC was not different between groups (Table 2). No correlation between surfactant kinetic parameters and patient characteristics were found, except for a negative correlation between surfactant half-life and gestational age in the $\mathrm{CDH}-$ ECMO group $(p=0.03)$.

The surfactant PC concentration in ELF during the first 4 days of the study was equal in both groups (Table 2). No correlations were found between the surfactant PC concentration and the clinical or surfactant PC kinetic parameters.

Surfactant PC concentration in ELF during the first 4 days of the study was not different between the survivors and non-survivors of the CDH-ECMO group $(9.5 \pm 3.6$ vs. $4.5 \pm 1.8 \mathrm{mg} / \mathrm{ml} \mathrm{ELF}, p=0.27)$. There were also no differences in surfactant kinetic parameters between the survivors and non-survivors of the $\mathrm{CDH}$ ECMO group. Non-survivors had a lower gestational age than survivors of the CDH-ECMO group $(37.1 \pm 0.6$ vs. $39.6 \pm 0.5$ weeks, $p=0.02$ ).

In the current study, we also measured fractional surfactant PC synthesis in two CDH patients who did not require ECMO. The kinetic parameters of these two $\mathrm{CDH}$ patients not requiring ECMO were: $T_{\text {app }} 13$ and $26 \mathrm{~h}$,
Fig. $1{ }^{13} \mathrm{C}$-enrichment of palmitic acid in surfactant phosphatidylcholine in sequential tracheal aspirates. Neonates with congenital diaphragmatic hernia on extracorporeal membrane oxygenation (CDH-ECMO) (closed circles) and control patients (open circles) received a $24-\mathrm{h}\left[\mathrm{U}-{ }^{13} \mathrm{C}\right]$ glucose infusion as precursor for phosphatidylcholine-palmitate in surfactant. Data are expressed as mean and standard error of the mean (SEM) of time intervals of 12 and $24 \mathrm{~h}$ (with the $24 \mathrm{~h}$ interval starting at $72 \mathrm{~h})$

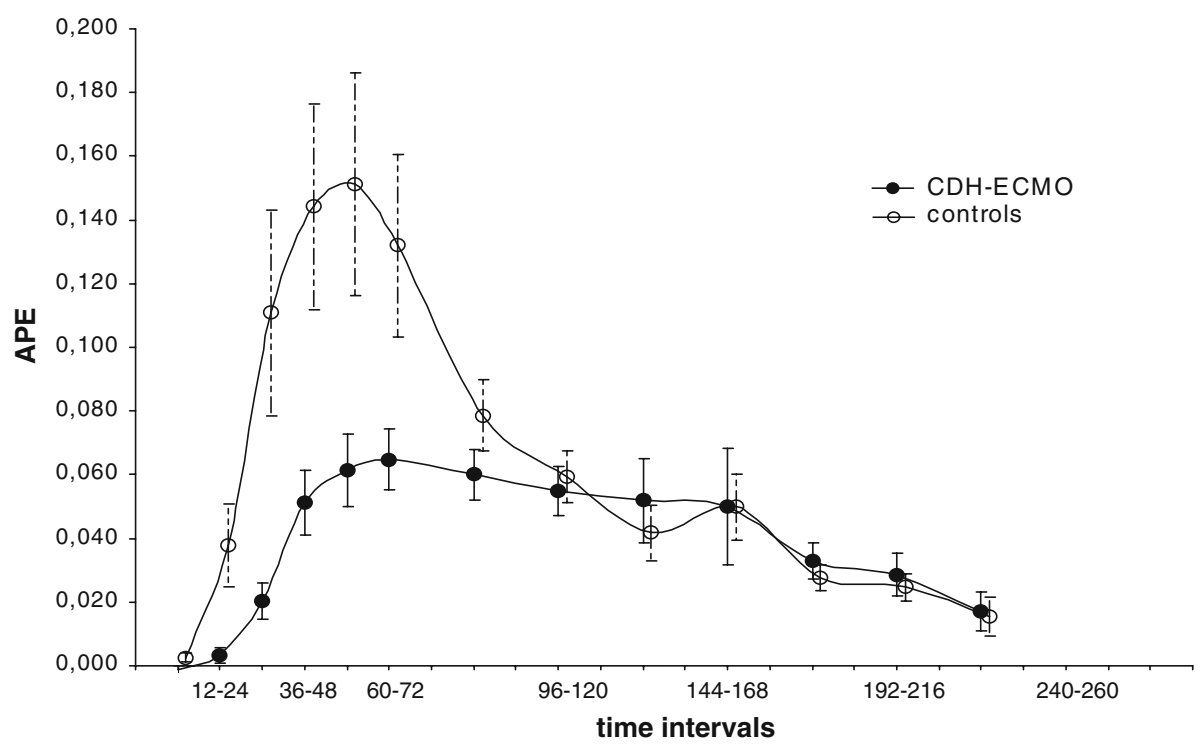


$T_{\max } 39$ and $43 \mathrm{~h}, E_{\max } 0.17$ and 0.23 APE, FSR 7 and $14 \% /$ day, PC concentration in ELF 3.7 and $7.6 \mathrm{mg} / \mathrm{ml}$, half-life $56.8 \mathrm{~h}$ in one patient only.

Seven CDH-ECMO patients and two control patients of the current study had also received an endotracheal tracer to calculate the total lung surfactant pool size [20]. By multiplying the FSR by the pool size in these patients, we were able to calculate the 'net absolute synthesis rate.' The mean net synthesis rate of seven CDH-ECMO patients was $2.7 \pm 0.8 \mathrm{mg} /(\mathrm{kg} \mathrm{d})$, which is comparable with that of premature infants [2.7 $\pm 0.8 \mathrm{mg} /(\mathrm{kg} \mathrm{d})]$ [29]. In the two control patients the net synthesis rate was much higher at 11.2 and $11.5 \mathrm{mg} /(\mathrm{kg} \mathrm{d})$.

\section{Discussion}

We report a significantly reduced surfactant $\mathrm{PC}$ synthesis in infants with $\mathrm{CDH}$ who require ECMO compared to ventilated control infants. The surfactant PC synthesis was studied in vivo with the use of stable isotopes by measuring incorporation rates of precursor glucose into surfactant $\mathrm{PC}$ (FSR $2.4 \pm 0.33$ vs. $8.0 \pm 2.4 \%$ /day, $p=0.04)$. These results are in line with studies in animal models that also found decreased PC synthesis in isolated type II cells or lungs from $\mathrm{CDH}$ fetuses of the rat and lamb model $[8,9,30]$.

In an earlier report in $\mathrm{CDH}$ infants who did not require ECMO, we found no decreased fractional synthesis rates of surfactant DSPC in comparison to ventilated control infants $[18,19]$. A plausible explanation for the difference in surfactant synthesis is that the $\mathrm{CDH}$ infants who require ECMO have more severe pulmonary hypoplasia and/or immaturity than $\mathrm{CDH}$ patients who do not require ECMO. Indeed, pulmonary insufficiency in the $\mathrm{CDH}$ infants who did not require ECMO in our two previous studies was clearly less severe with a lower OI (7.8-10 vs. 40.6), other ventilator parameters and a lower mortality. In agreement with our previous studies, the kinetic parameters of the two $\mathrm{CDH}$ patients not requiring ECMO were very similar to these in the ventilated control group.

The decrease in surfactant synthesis in this study on CDH-ECMO patients is felt to be secondary to progressing injury to the lungs. Bohlin et al. [31] measured surfactant synthesis in term infants using ${ }^{13} \mathrm{C}$-acetate as precursor. They found a decreased FSR in term infants with severe respiratory failure, similar to the FSR of preterm infants with respiratory distress syndrome, suggesting that a lower FSR might be reflective of severely injured and dysfunctional lungs. The FSR we found in our CDH patients is also similar to the FSR in preterm infants with RDS ( $\sim 2.7 \%$ /day) after ${ }^{13} \mathrm{C}$-glucose infusion as precursor [24].

Our results of a lower FSR in CDH-ECMO cannot be simply explained by the smaller size of the lungs. Firstly, if pool size were just decreased in relation to smaller lungs, FSR would not be influenced when synthesis per lung unit would remain the same. Secondly, we did not find a decreased PC pool size in our previous study on CDH-ECMO patients in comparison to infants with meconium aspiration on ECMO or to non-ECMO patients [20]. Thirdly, no difference in net absolute synthesis between CDH infants without ECMO and ventilated controls was found by the use of dual tracers [18]. The net absolute synthesis rate calculated in seven CDH-ECMO patients is comparable with that of premature infants [2.7 $\pm 0.8 \mathrm{mg} /(\mathrm{kg} \mathrm{d})]$ [29]. In the two control patients the net synthesis rate was much higher.

An alternative explanation for the decreased surfactant synthesis in CDH-ECMO patients is the severe pulmonary hypertension leading to ECMO requirement. It could be speculated that reduced blood flow through the lungs due to severe pulmonary hypertension provides less substrate for surfactant synthesis. In addition, during VA-ECMO the lung blood flow is also significantly lower since the circuit blood flow drained from the right atrium is shunting the lungs and directly diverted to the ascending aorta. Earlier we found an increased surfactant synthesis in premature infants who had a clinically relevant persistent ductus arteriosus, a situation that leads to an increased lung blood flow [29]. Furthermore, ECMO is known to result in increased vascular permeability and cytokine release, which could influence surfactant kinetics [32].

From animal studies it is known that physical stretch of the alveoli stimulates surfactant synthesis and secretion [33]. Physical stretch during ECMO treatment is reduced because low ventilatory settings (PIP 9-12 mmHg) are used as part of the concept of "lung rest" and could possibly decrease surfactant synthesis. However, we found no difference in surfactant synthesis in preterm infants ventilated with high frequency oscillation compared to conventional ventilation, which argues against the influence of stretch in vivo on surfactant synthesis [34].

In the current study we did not find a significant difference in the concentration of PC in ELF during the first 4 days between the $\mathrm{CDH}$ patients on ECMO and controls (Table 2). The PC concentration in ELF of the CDHECMO patients in this study $(6.6 \mathrm{mg} / \mathrm{ml})$ is comparable with other data of CDH patients on ECMO $(\sim 6.5 \mathrm{mg} / \mathrm{ml})$ and with the results of $\mathrm{CDH}$ patients not requiring ECMO $(\sim 4 \mathrm{mg} / \mathrm{ml})[16,19,20]$. In preterm infants, using the same method, a lower surfactant PC concentration was found $(2.4 \mathrm{mg} / \mathrm{ml})$ [35]. Earlier, we showed that surfactant PC pool size in CDH patients requiring ECMO was not decreased when compared with the pool sizes of neonates with meconium aspiration syndrome requiring ECMO and neonates who did not require ECMO [20]. However, Cogo et al. found lower concentrations of DSPC in ELF and SP-A in tracheal aspirates of CDH patients who were not on ECMO compared to controls.

Surfactant PC concentration in ELF during the study was not significantly lower in the non-survivors of our 
CDH-ECMO group, though in the literature a correlation between surfactant composition and survival have been mentioned $[12,36]$.

In conclusion, the surfactant $\mathrm{PC}$ synthesis in neonates with $\mathrm{CDH}$ on ECMO is decreased compared to ventilated control patients. Our study does not completely solve the problem of which mechanism is responsible for this decreased synthesis. In fact, it would have been better if we also included another $\mathrm{CDH}$ no ECMO group to compare, which would be more convincing to show the relation of the severity of the $\mathrm{CDH}$ on the surfactant metabolism. As in previous studies, we did not find a decreased DSPC synthesis in milder CDH patients who did not require ECMO, and we therefore speculate that the decreased PC synthesis in CDH-ECMO patients is related to the severity of the pulmonary insufficiency, either caused by immaturity or by ventilator-induced injury, and/or by the low pulmonary blood flow during severe pulmonary hypertension and especially during ECMO. This is also supported by the study of Boucherat et al. [15] who found no deficient surfactant storage in human fetuses with CDH. From the present study it has become clear that $\mathrm{CDH}$ patients who require ECMO are quite a different group of patients than those with $\mathrm{CDH}$ without ECMO. The ECMO patients have a structural and functional pulmonary immaturity that sets them apart [37].

Acknowlegdments We thank Roel Venrooij (medical student, Erasmus MC, Rotterdam, The Netherlands) for technical support, Wim van den Berg (Internal Medicine, Erasmus MC-Dijkzigt, Rotterdam, The Netherlands) for technical support, and the nursing staff, neonatologists and intensivists of the neonatal and surgical intensive care units of the Erasmus MC-Sophia for their help and support during the study. We appreciate the Sophia Foundation for Medical Research (SSWO 245), Rotterdam, The Netherlands (LJZ and DT) and NIH R01 HL 65385 (AH).

Open Access This article is distributed under the terms of the Creative Commons Attribution Noncommercial License which permits any noncommercial use, distribution, and reproduction in any medium, provided the original author(s) and source are credited.

\section{References}

1. Sakurai Y, Azarow K, Cutz E, Messineo A, Pearl R, Bohn D (1999) Pulmonary barotrauma in congenital diaphragmatic hernia: a clinicopathological correlation. J Pediatr Surg 34:1813-1817

2. Stege G, Fenton A, Jaffray B (2003) Nihilism in the 1990s: the true mortality of congenital diaphragmatic hernia. Semin Perinatol 29:112-117

3. Kays DW, Langham MR Jr, Ledbetter DJ, Talbert JL (1999) Detrimental effects of standard medical therapy in congenital diaphragmatic hernia. Ann Surg 230:340-348

4. Boloker J, Bateman DA, Wung JT, Stolar CJ (2002) Congenital diaphragmatic hernia in 120 infants treated consecutively with permissive hypercapnia/spontaneous respiration/ elective repair. J Pediatr Surg 37:357366

5. Alfonso LF, Arnaiz A, Alvarez FJ, Qi B, Diez-Pardo JA, Vallis-i-Soler A, Tovar JA (1996) Lung hypoplasia and surfactant system immaturity induced in the fetal rat by prenatal exposure to nitrofen. Biol Neonate 69:94-100

6. Mysore MR, Margraf LR, Jaramillo MA, Breed DR, Chau VL, Arevalo M, Moya FR (1998) Surfactant protein A is decreased in a rat model of congenital diaphragmatic hernia. Am J Respir Crit Care Med 157:654-657
7. Utsuki T, Hashizume K, Iwamori M (2001) Impaired spreading of surfactant phospholipids in the lungs of newborn rats with pulmonary hypoplasia as a model of congenital diaphragmatic hernia induced by nitrofen. Biochim Biophys Acta 1531:90-98

8. Glick PL, Stannard VA, Leach CL, Rossman J, Hosada Y, Morin FC, Cooney DR, Allen JE, Holm B (1992) Pathophysiology of congenital diaphragmatic hernia II: the fetal lamb $\mathrm{CDH}$ model is surfactant deficient. J Pediatr Surg 27:382-387

9. Wilcox DT, Glick PL, Karamanoukian HL, Holm BA (1997) Contributions by individual lungs to the surfactant status in congenital diaphragmatic hernia. Pediatr Res 41:686-691

10. van Tuyl M, Blommaart PE, Keijzer R, Wert SE, Ruijter JM, Lamers WH, Tibboel D (2003) Pulmonary surfactant protein $\mathrm{A}, \mathrm{B}$, and $\mathrm{C}$ mRNA and protein expression in the nitrofen-induced congenital diaphragmatic hernia rat model. Pediatr Res 54:641-652

11. Sullivan KM, Hawgood S, Flake AW, Harrison MR, Adzick NS (1994) Amniotic fluid phospholipid analysis in the fetus with congenital diaphragmatic hernia. J Pediatr Surg 29:1020-1023

12. Moya FR, Thomas VL, Romaguera J, Mysore MR, Maberry M, Bernard A, Freund M (1995) Fetal lung maturation in congenital diaphragmatic hernia. Am J Obstet Gynecol 173:1401-1405
13. Asabe K, Tsuji K, Handa N, Kurosaka N, Kajiwara M (1997) Immunohistochemical distribution of surfactant apoprotein-A in congenital diaphragmatic hernia. J Pediatr Surg 32:667-672

14. Minowa $\mathrm{H}$, Takahashi $\mathrm{Y}$, Kawaguchi $\mathrm{C}$, Sadou T, Konishi N, Nishikubo T, Yoshioka A (2000) Expression of intrapulmonary surfactant apoprotein-A in autopsied lungs: comparative study of cases with or without pulmonary hypoplasia. Pediatr Res 48:674-678

15. Boucherat O, Benachi A, Chailley-Heu B, Franco-Montoya M, Elie C, Martinovic J, JR B (2007) Surfactant maturation is not delayed in human fetuses with diaphragmatic hernia. PLoS Med 4:e237

16. IJsselstijn H, Zimmermann LJI, Bunt JEH, de Jongste JC, Tibboel D (1998) Prospective evaluation of surfactant composition in bronchoalveolar lavage fluid of infants with congenital diaphragmatic hernia and of agematched controls. Crit Care Med 26:573-580

17. Cogo P, Zimmermann LJ, Meneghini L, Mainini N, Bordignon L, Suma V, Buffo M, Carnielli VP (2003) Pulmonary surfactant disaturatedphosphatidylcholine (DSPC) turnover and pool size in newborn infants with congenital diaphragmatic hernia (CDH). Pediatr Res 54:653-658 
18. Cogo P, Zimmermann LJ, Verlato G, Midrio P, Gucciardi A, Ori C, Carnielli VP (2004) A dual stable isotope tracer method for the measurement of surfactant disaturatedphosphatidylcholine net synthesis in infants with congenital diaphragmatic hernia. J Pediatr 56:184-190

19. Cogo PE, Zimmermann LJ, Rosso F, Tormena F, Gamba P, Verlato G, Baritussio A, Carnielli VP (2002) Surfactant synthesis and kinetics in infants with congenital diaphragmatic hernia. Am J Respir Crit Care Med 166:154-158

20. Janssen DJ, Tibboel D, Carnielli V, van Emmen E, Luijendijk IH, Wattimena JL, Zimmermann L (2003) Surfactant phosphatidylcholine pool size in human neonates with congenital diaphragmatic hernia requiring ECMO. J Pediatr 142:247-252

21. Van Meurs K (2004) Is surfactant therapy beneficial in the treatment of the term newborn infant with congenital diaphragmatic hernia? J Pediatr 145:312-316

22. Colby LK CE, Lally KP, Hintz SR, Lally PA, Tibboel D, Moya FR, Van Meurs KP, Congenital Diaphragmatic Hernia Study Group (2004) Surfactant replacement therapy on ECMO does not improve outcome in neonates with congenital diaphragmatic hernia. J Pediatr Surg 39:1632-1637

23. Shehata SM, Tibboel D, Sharma HS, Mooi WJ (1999) Impaired structural remodelling of pulmonary arteries in newborns with congenital diaphragmatic hernia: a histological study of 29 cases. J Pathol 189:112-118

24. Bunt JE, Zimmermann LJ, Wattimena JL, van Beek RH, Sauer PJ, Carnielli VP (1998) Endogenous surfactant turnover in preterm infants measured with stable isotopes. Am J Respir Crit Care Med 157:810-814
25. Pfaffenberger CD, Szafranek J, Horning MG, Horning EC (1975) Gas chromatographic determination of polyols and aldoses in human urine as polyacetates and aldonitrile polyacetates. Anal Biochem 63:501512

26. Bligh EG, Dyer WJ (1959) A rapid method of total lipid extraction and purification. Can J Biochem Physiol 37:911-917

27. Touchstone JC, Chen JC, Beaver KM (1979) Improved separation of phospholipids in thin layer chromatography. Lipids 15:61-62

28. Hallman M, Merritt TA, Akino T, Bry K (1991) Surfactant protein A, phosphatidylcholine, and surfactant inhibitors in epithelial lining fluid. Correlation with surface activity, severity of respiratory distress syndrome, and outcome in small premature infants. Am Rev Respir Dis 144:1376-1384

29. Bunt JE, Carnielli VP, Janssen DJ, Wattimena JL, Hop WC, Sauer PJ, Zimmermann LJ (2000) Treatment with exogenous surfactant stimulates endogenous surfactant synthesis in premature infants with respiratory distress syndrome. Crit Care Med 28:3383-3388

30. Zimmermann L, IJsselstijn H, Scheffers E, Sayer P, JJ B, Tibboel D (1994) Decreased activity of phosphocholine citidyltransferase in type II pneumocytes from rats with congenital diaphragmatic hernia. Pediatr Res 35:359A

31. Bohlin K, Merchak A, Spence K, Patterson BW, Hamvas A (2003) Endogenous surfactant metabolism in newborn infants with and without respiratory failure. Pediatr Res 54:185191
32. Fortenberry JD, Bhardwaj V, Niemer P, Cornish JD, Wright JA, Bland L (1996) Neutrophil and cytokine activation with neonatal extracorporeal membrane oxygenation. J Pediatr 128:670-678

33. Scott JE, Yang SY, Stanik E, Anderson JE (1993) Influence of strain on [3H]thymidine incorporation, surfactant-related phospholipid synthesis, and cAMP levels in fetal type II alveolar cells. Am J Respir Cell Mol Biol 8:258-265

34. Merchak A, Janssen DJ, Bohlin K, Patterson BW, Zimmermann LJ, Carnielli VP, Hamvas A (2002) Endogenous pulmonary surfactant metabolism is not affected by mode of ventilation in premature infants with respiratory distress syndrome. J Pediatr 140:693-698

35. Bunt JE, Carnielli VP, Darcos Wattimena JL, Hop WC, Sauer PJ, Zimmermann LJ (2000) The effect in premature infants of prenatal corticosteroids on endogenous surfactant synthesis as measured with stable isotopes. Am J Respir Crit Care Med 162:844-849

36. Lotze A, Whitsett JA, Kammerman LA, Ritter M, Taylor GA, Short BL (1990) Surfactant protein A concentrations in tracheal aspirate fluid from infants requiring extracorporeal membrane oxygenation. J Pediatr 116:435-440

37. Davey M (2007) Surfactant levels in congenital diaphragmatic hernia. PLoS Med 4:e237 